\title{
Do we need randomized clinical trials in extracorporeal respiratory support? No
}

\author{
Luciano Gattinoni* and Michael Quintel
}

๑๐ 2017 Springer-Verlag GmbH Germany and ESICM

\section{Introduction}

Extracorporeal lung support (here collectively referred to as ECMO, though inappropriately) is available in largely different configurations, as known for decades (Fig. 1) [1], and is applied for two primary purposes: as rescue therapy or as supportive therapy. In general, the effectiveness of a given therapy is proved by randomized controlled trials (RCTs), which, to be meaningful, must meet three conditions [2]:

1. The theory must be biologically plausible.

2. The hypothesis must be clear and the experiment appropriately designed.

3. The RCT must be feasible (number of patients, timing, and cost).

Are meaningful ECMO trials possible?

\section{ECMO as rescue therapy for hypoxemia}

It is not easy to define in theory what degree of hypoxemia requires a rescue therapy. The clinical condition demanding rescue is the one in which the physician assesses hypoxemia as so severe that a given patient is going to die [3]. It is nearly impossible to characterize this situation with numbers. $\mathrm{A} \mathrm{PaO}_{2}$ of $30 \mathrm{mmHg}$ may be perfectly well tolerated in a young man with robust cardiovascular response, while it may be lethal in an elderly patient with comorbidities. The knowledge of the trajectory of the underlying disease, associated with a series of non-quantifiable signs, makes the attending physician the best available judge to define if a given patient requires

\footnotetext{
*Correspondence: gattinoniluciano@gmail.com

Department of Anesthesiology, Emergency and Intensive Care Medicine, University of Göttingen, Robert-Koch-Straße 40, 37075 Göttingen, Germany
}

For contrasting viewpoints, please go to doi: 10.1007/s00134-017-4930-x and doi: 10.1007/s00134-017-4933-7.

\section{Springer}

rescue. In rescue conditions, the intervention cannot be ethically randomized (lack of equipoise). This compares well to the organ transplantation: over the years, the indications for the recipients and the requirements for organ quality have deeply changed, but, for lack of equipoise, nobody ever proposed to use randomization to receive an organ or not.

\section{ECMO as "ordinary" therapy}

The first requisite for a meaningful trial is the biological plausibility. Indeed, there must be a solid rationale to hypothesize that one of the possible ECMO configurations provides benefit compared to mechanical ventilation, i.e., the ECMO-induced injury (in the tested configuration) is lower than the ventilator-induced lung injury (VILI).

\section{ECMO as adjunct to mechanical ventilation}

It is difficult to find a biological rationale for which adding oxygen to the venous blood should decrease the damage of mechanical ventilation. Anytime we artificially increase the mixed venous oxygen saturation adding oxygen via the artificial lung, we increase the oxygen flow through the shunted area but we decrease proportionally the oxygen transfer through the natural lung. The oxygenation increases by a few points (as a result of the better $\mathrm{PO}_{2}$ of the shunted blood), while the oxygen transport increases marginally. It is difficult to figure out why the outcome should improve under these conditions, i.e., when ECMO is applied as an adjunct. Surprisingly, however, ECMO is usually applied in this configuration: most of the oxygen is added to the venous blood by the artificial lung, while the mechanical ventilation remains substantially unmodified [4]. A trial that would randomize this configuration against the standard therapy lacks, in our opinion, biological plausibility; or if there is one, it is beyond our reasoning. 


\begin{tabular}{|c|c|c|c|}
\hline & $\begin{array}{c}\text { Renal } \\
\text { haemodialysis }\end{array}$ & $\begin{array}{l}\text { Extracorporcal } \\
\text { removal of } \\
\text { carbon dioxide }\end{array}$ & $\begin{array}{c}\text { Extracorporcal } \\
\text { oxygenation }\end{array}$ \\
\hline $\begin{array}{l}\text { Extracorporeal blood } \\
\text { flow }\left(\mathrm{ml} \mathrm{min}^{-1}\right)\end{array}$ & $200-300$ & $500-1000$ & $2000-4000$ \\
\hline $\begin{array}{l}\text { Blood pumping } \\
\text { Haemodynamic changes } \\
\text { Vascular access }\end{array}$ & $\begin{array}{l}\text { optional } \\
\text { small } \\
\mathrm{A}-\mathrm{V} \text { shunt }\end{array}$ & $\begin{array}{l}\text { optional } \\
\text { small } \\
A-V \text { shunt }\end{array}$ & $\begin{array}{l}\text { required } \\
\text { major } \\
\mathrm{V}-\mathrm{A}\end{array}$ \\
\hline & $\mathrm{A}-\mathrm{V}$ fistula & $\begin{array}{l}\text { or } \\
A-V \text { fistula } \\
\text { or } \\
V-V \text { pumping }\end{array}$ & $\begin{array}{c}\text { or } \\
V-V\end{array}$ \\
\hline $\begin{array}{l}\text { Surgical complexity } \\
\text { Complexity of equipment } \\
\text { Requirement for heparin }\end{array}$ & $\begin{array}{l}\text { simple } \\
\text { moderate } \\
\text { small }\end{array}$ & $\begin{array}{l}\text { simple } \\
\text { simple } \\
\text { small }\end{array}$ & $\begin{array}{l}\text { complex } \\
\text { advanced } \\
\text { large }\end{array}$ \\
\hline
\end{tabular}

Fig. 1 This figure, designed in 1978, underlines that the extracorporeal flows are the main factors for $\mathrm{CO}_{2}$ removal and/or oxygen supply. That some $\mathrm{CO}_{2}$ was removed by kidney dialysis, inducing hypoxemia, was already known. Many other hypotheses present in the figure were realized years later, such as the low-flow arteriovenous support (Reproduced with permission from L. Gattinoni et al. [1])

\section{ECMO as complement to mechanical ventilation}

This configuration takes advantage of extracorporeal $\mathrm{CO}_{2}$ removal $\left(\mathrm{ECCO}_{2} \mathrm{R}\right)$ to deeply modify mechanical ventilation, focusing on reducing or abolishing VILI. This approach, which may vary from complete lung rest [5] to moderately low tidal volume through the low respiratory rate [6], is rational only if the population tested has a high probability of VILI. This is far greater in patients with a smaller and inhomogeneous "baby lung" (conditions more frequently observed in severe ARDS). Therefore, a randomized trial would be meaningful (i.e., sufficient biological plausibility) only in severe ARDS patients, where the extracorporeal respiratory support is applied as a complement to mechanical ventilation. In patients with lower probability of VILI, the rationale of applying extracorporeal support is more questionable, as the ECMOrelated complications [7] may outweigh those related to ventilation.

\section{ECMO as alternative to mechanical ventilation}

This is in theory an appealing hypothesis to be tested: no mechanical ventilation, no VILI. This implies that to avoid VILI nothing is better than spontaneous breathing. However, Mascheroni and Kolobow, years in advance of the current thinking, showed the deleterious effects of high-volume spontaneous breathing in sheep [8]. Further, it is a consistent finding that, in full-blown ARDS, independently of gas exchange, even during ECMO, the respiratory drive might be so high that it induces tremendous stress and strain. Therefore, an RCT comparing spontaneous breathing with ECMO and mechanical ventilation lacks biological plausibility.

\section{Feasibility of RCTs comparing ECMO and mechanical ventilation}

Once the biological plausibility has been ensured, it is necessary to assess the feasibility of the trial, by first defining the sample size. This requires an estimate of the fraction of mortality attributable to VILI. It is difficult to hypothesize values greater than those found between high and low tidal volume in the ARMA trial (i.e., not exceeding 10\%) [9]. To prove this extraordinary and optimistic difference of mortality between ECMO and conventional therapy in a population with $50 \%$ baseline mortality, the sample size required is 782 patients (i.e., 391 patients per group). The average enrolment rate of the largest RCTs in ARDS is 0.58 patients/ICU/ month. Considering only the severe ARDS, it would be 0.14 patients/ICU/month. It will take 15.5 years for 30 ICUs to complete the recruitment for such a trial.

\section{Ongoing RCTs}

The EOLIA trial [10] was designed to find a $20 \%$ absolute mortality difference between ECMO and control group. For the trial to be "positive" it is necessary that the fraction of mortality due to VILI is $20 \%$, that VILI completely disappears in the ECMO group, and that the mortality attributable to ECMO is $0 \%$. Such findings are extremely unlikely if not unrealistic. Therefore we believe that there is no chance of ending up with a "positive" trial. Nonetheless the trial will provide important information and certainly teach us something.

The SUPERNOVA trial [11] aims to provide an ultraprotective lung strategy (tidal volume lower than $4 \mathrm{ml} /$ $\mathrm{kg}$ PBW) in patients with moderate ARDS. A pilot study is actually underway. We may wonder, however, what change in mortality we may expect on decreasing the tidal volume from 6 to $4 \mathrm{ml} / \mathrm{kg}$ PBW in a moderate ARDS population, where the chances of developing VILI are undoubtedly lower than in the severe ARDS population. Further, if PEEP is not increased in this population, lifethreatening hypoxemia may be anticipated, as a result of the reduction of mean airway pressure $[12,13]$. The rationale for such an RCT is weak and anyway it is hard to expect, in moderate ARDS patients (having a ca. 30\% baseline mortality), a mortality attributable to VILI of greater than $5 \%$. Therefore, to be successful, a trial comparing a SUPERNOVA-like patient with moderate ARDS would require a sample size of about 2600 patients; it would require decades.

\section{Final remarks}

These RCTs will be conducted anyway, with unavoidable negative results and potentially devastating 
consequences, such as the first trial on ECMO [14], which led to ECMO being banned for three decades. There is enormous scope for research, however, such as on the conditions leading to better lung healing, a so far completely unexplored field. Indeed, ECMO allows the largest possible spectrum of lung treatment, from complete rest to whatever form of lung movement imaginable. Which one is the best? This will be a field for new theories, hypotheses, and, in the end, meaningful trials.

\section{Compliance with ethical standards}

\section{Conflicts of interest}

On behalf of all authors, the corresponding author states that there is no conflict of interest.

\section{Ethical approval}

This article does not contain any studies with human participants or animals performed by any of the authors.

Received: 24 April 2017 Accepted: 27 April 2017

Published online: 25 September 2017

\section{References}

1. Gattinoni L et al (1978) Control of intermittent positive pressure breathing (IPPB) by extracorporeal removal of carbon dioxide. Br J Anaesth 50(8):753-758. doi:10.1093/bja/50.8.753

2. Gattinoni L, Giomarelli P (2015) Acquiring knowledge in intensive care: merits and pitfalls of randomized controlled trials. Intensive Care Med 41(8):1460-1464
3. Moerer O, Tonetti T, Quintel M (2017) Rescue therapies for acute respiratory distress syndrome: what to try first? Curr Opin Crit Care 23(1):52-59

4. Gattinoni L, Tonetti T, Quintel M (2017) How best to set the ventilator on extracorporeal membrane lung oxygenation. Curr Opin Crit Care 23(1):66-72

5. Kolobow T et al (1978) An alternative to breathing. J Thorac Cardiovasc Surg 75(2):261-266

6. Gattinoni L et al (1986) Low-frequency positive-pressure ventilation with extracorporeal $\mathrm{CO} 2$ removal in severe acute respiratory failure. JAMA 256(7):881-886

7. Fan E et al (2016) Venovenous extracorporeal membrane oxygenation for acute respiratory failure: a clinical review from an international group of experts. Intensive Care Med 42(5):712-724

8. Mascheroni $D$ et al (1988) Acute respiratory failure following pharmacologically induced hyperventilation: an experimental animal study. Intensive Care Med 15(1):8-14

9. Acute Respiratory Distress Syndrome Network, Brower RG, Matthay MA, Morris A, Schoenfeld D, Thompson BT, Wheeler A (2000) Ventilation with lower tidal volumes as compared with traditional tidal volumes for acute lung injury and the acute respiratory distress syndrome. N Engl I Med 342(18):1301-1308

10. Combes A. Extracorporeal membrane oxygenation for severe acute respiratory distress syndrome (EOLIA). https://clinicaltrials.gov/ct2/show/ NCT01470703. Accessed 20 April 2017

11. SUPERNOVA. SUPERNOVA: a strategy of ultraprotective lung ventilation with extracorporeal $\mathrm{CO} 2$ removal for new-onset moderate to severe ARDS. http://www.esicm.org/research/trials-group/supernova. Accessed $1 \mathrm{Mar} 2017$.

12. Fanelli V et al (2016) Feasibility and safety of low-flow extracorporeal carbon dioxide removal to facilitate ultra-protective ventilation in patients with moderate acute respiratory distress syndrome. Crit Care 20:36

13. Gattinoni L (2016) Ultra-protective ventilation and hypoxemia. Crit Care 20(1):130

14. Zapol WM et al (1979) Extracorporeal membrane oxygenation in severe acute respiratory failure. A randomized prospective study. JAMA 242(20):2193-2196 